\title{
PEMANFAATAN DATA GELOMBANG KEJUT UNTUK MENGETAHUI MANFAAT PITA GETAR DI JALAN RAYA
}

\author{
Muhammad Idham ${ }^{1}$, Hendra Saputra ${ }^{2}$ \\ 1,2 Jurusan Teknik Sipil, Politeknik Negeri Bengkalis, Jl. Bathin Alam, Sei. Alam, Bengkalis, Riau \\ Email: ${ }^{1}$ idham@polbeng.ac.id
}

\begin{abstract}
The rumble strips have been done in Bengkalis regency especially in Bengkalis island. The purpose of rumble strips can be able to answer a challenge to safety traffic. However, visually the use of rumble strips has not been exploited by road users. This research by using shockwave theory to get speed before and after which is supported by a greenshield method. The result of this research showed that speed of vehicles decreases below the speed of the road plan $25,07 \mathrm{~km} / \mathrm{h}$ with shockwave $9,93 \mathrm{~km} / \mathrm{h}$. It indicated that the mathematical calculations with rumble strips can reduce the speed of the vehicle.
\end{abstract}

Key words : Rumble strips, speed, greenshield, shock wave

\begin{abstract}
ABSTRAK
Penggunaan pita getar sudah mulai banyak digunakan di kabupaten Bengkalis khususnya di pulau Bengkalis. Tujuan penggunaan pita getar adalah mampu menjawab tantangan terhadap keselamatan berlalu lintas. Akan tetapi, secara visual penggunaan pita getar belum sepenuhnya dumanfaatkan oleh pengguna jalan raya. Peneitian ini dilakukan dengan menggunakan teori gelombang kejut untuk mendapatkan kecepatan sebelum dan sesudah yang dibantu dengan mengguna metode greenshields, dimana hasil dari penelitian ini didapat bahwa kecepatan kendaraan turun dibawah kecepatan rencana jalan 25,07 km/jam dengan nilai gelombang kejut 9,93 km/jam. Hal ini menunjukkan bahwa secara perhitungan matematika penggunaan pita getar mampu mengurangi kecepatan kendaraan.
\end{abstract}

Kata kunci : Pita getar, kecepatan, greenshield, gelombang kejut

\section{PENDAHULUAN}

Ruang lingkup permasalahan transportasi mencakup beberapa hal, salah satunya adalah kebutuhan akan pergerakan. Kebutuhan akan pergerakan terjadi karena adanya kebutuhan untuk mencapai asal menuju tempat tujuan. Permasalahannya adalah untuk mencapai tujuan pergerakan selalu mengalami konflik lalu lintas baik dari segi keamanan dan kenyamanan dari pengguna jalan lainnya, khususnya di kabupaten Bengkalis. Salah satu gangguan yang seri terjadi di lapangan adalah adanya kendaraan yang bergerak diatas kecepatan maksimum yang diizinkan oleh jalan tersebut (Idham, 2015).
Untuk mengurangi kecepatan kendaraan serta memberikan efek getaran sehingga pengemudi kendaraan menjadi sadar maka melalui Dinas Perhubungan kabupaten Bengkalis menerapkan pemasangan pita getar disetiap jalan yang dianggap bermasalah/konflik. Permasalahan yang muncul adalah pita getar yang terpasang secara visual terlihat hanya sekedar terpasang karena banyak pengemudi tidak mengurangi kecepatan, sehingga perlu dilakukan kajian matematis dari pemanfaatan data gelombang kejut sebagai bahan evaluasi dari penggunaan pita getar di lapangan (Idham, 2017). 


\section{METODE PENELITIAN}

Tahapan pada penelitian akan dijabarkan dalam bentuk bagan alir pada Gambar 1. Penetapan dan penentuan titik lokasi penelitian didasarkan kepada analisa konflik arus lalu lintas terpadat dan tersibuk, dimana lokasi yang dipilih adalah di Jalan Jenderal Sudirman, Kecamatan Bengkalis dengan titik pengamatan sesuai dengan yang diilustrasikan seperti pada Gambar 2.

Pada tahapan penelitian ini merupakan turunan dari penelitian sebelumnya dan penelitian lanjutan yang akan direncanakan oleh peneliti yang akan dikembangkan.

\section{HASIL dan PEMBAHASAN}

Volume lalu lintas yang digunakan pada penelitian ini merupakan volume lalu lintas selama 40 jam yang dilaksanakan selama 5 hari dengan pembagian waktu pelaksanaan survei 8 jam/hari. Adapun rekapitulasi data survei volume lalu lintas terdapat pada Tabel 1.

Hubungan matematis antara volume, kecepatan, dan kepadatan pada hari Senin 12 Maret 2018 sebagai contoh perhitungan dan tabulasi maka dapat dilihat pada Tabel 2. Hubungan matematis antara kecepatan-kepadatan, volume-kepadatan, dan volumekecepatan dapat dilihat pada Tabel 3. Hubungan kepadatan dan volume dapat dilihat pada Gambar 3.

Dengan menggunakan persamaan 2.13, maka akan didapat nilai dari gelombang kejut akibat dari adanya pita getar (rumble strip) dari 3 (tiga) titik yang disurvei yaitu :

$\omega_{\mathrm{AB}}=\frac{0-497,4}{41-25,07}=\frac{-497,4}{16,4}=-30,299 \mathrm{~km} / \mathrm{jam}$
Berdasarkan nilai gelombang kejut yang didapat pada hari Senin untuk 3 (tiga) pita getar (rumble strip) menunjukkan bahwa terjadinya penurunan kecepatan dari kecepatan rencana jalan sesuai dengan kelas jalan yaitu $60 \mathrm{~km} / \mathrm{jam}$ (kelas jalan III/C) yaitu sebesar -30,299 $\mathrm{km} / \mathrm{jam}$ (nilai gelombang kejut).

\section{KESIMPULAN}

1. Hasil survei di 3 (tiga) pita getar (rumble strips) menunjukkan bahwa kecepatan kendaraan turun di bawah kecepatan rencanan jalan yaitu 30,299 $\mathrm{km} / \mathrm{jam}$ yang seharusnya 40 $\mathrm{km} / \mathrm{jam}$ (kelas jalan III C/Lokal) sesuai dengan PP 34 Tahun 2006.

2. Nilai gelombang kejut pada ruas jalan yang diteliti sebesar antara 10 $15 \mathrm{~km} / \mathrm{jam}$ pada 40 jam waktu survei selama 1 (satu) minggu.

3. Nilai gelombang kejut menunjukkan bahwa adanya pengurang kecepatan kendaraan sesudah melewati pita getar (rumble strips) sehingga pita getar dapat difungsikan selain sebagai efek kejut bagi kendaraan tetapi juga sebagai penurun kecepatan kendaraan.

\section{DAFTAR PUSTAKA}

[1] Brouwer, S,V., Liauner, J., dan Setiawan, R. 2015. "Efektifitas pita pengaduh untuk mereduksi kecepatan kendaraan bermotor", Jurnal FSTPT International Symposium.

[2] Edige, J.B., Ghaemi, S.M., dan Mashris, N. 2013. Prevelence of Traffic Kinematic Wave at Priority Junction With Entry Hump, Malaysian Journal of Civil Engineering, Vol. 25, No. 2, pp. 168-176.

[3] Hobbs, F., D. 1995. Perencanaan dan Teknik Lalu-lintas, Gadjah Mada University Press. 
[4] H.W.Leibowitz. 1985. Grade crossing accident and human faktor engineering, Jurnal American Scientist, Volume 73 no. 6 hal.

[5] Michael J. C, Jame W.S.(1993) Rumble Strips and Pedestrian Savet Jurnal ITE.

558-562.

Tabel 1. Volume Lalu Lintas dan Jumlah Sampel

\begin{tabular}{|c|c|c|c|c|c|}
\hline \multirow{2}{*}{ No } & \multirow{2}{*}{ Jenis Kendaraan } & \multicolumn{2}{|c|}{$\begin{array}{l}\text { Arah Pergerakan Lalu } \\
\text { Lintas }\end{array}$} & \multirow{2}{*}{$\begin{array}{c}\text { Total } \\
\text { Kendaraan }\end{array}$} & \multirow{2}{*}{$\begin{array}{l}\text { Jumlah Sampel } \\
\text { (Kendaraan) }\end{array}$} \\
\hline & & B-T & T-B & & \\
\hline 1 & Sepeda Motor & 29.020 & 28.291 & 57.311 & 397 \\
\hline 2 & Kend. Ringan & 2.975 & 2.764 & 5.739 & 374 \\
\hline 3 & Kenda. Sedang & 161 & 198 & 359 & 189 \\
\hline \multirow[t]{2}{*}{4} & Kend. Berat & 2 & 2 & 4 & 4 \\
\hline & & & & 63.413 & 594 \\
\hline
\end{tabular}

Sumber : Data survei lapangan (2018) diolah

Tabel 2. Hubungan Matematis Antara Volume, Kecepatan dan Kepadatan

\begin{tabular}{|c|c|c|c|c|c|c|c|c|c|}
\hline \multirow{3}{*}{ Data } & \multirow{3}{*}{ Periode } & \multicolumn{3}{|c|}{ Faktor Konversi } & \multirow{2}{*}{$\begin{array}{c}\text { Volume } \\
(\mathrm{V}) \\
\text { (SMP/ } \\
\text { jam) }\end{array}$} & \multirow{2}{*}{$\begin{array}{c}\text { Us } \\
\text { (km/ } \\
\text { jam) }\end{array}$} & \multirow{2}{*}{$\begin{array}{c}\text { Density } \\
(\mathrm{SMP} / \\
\mathrm{km})\end{array}$} & \multirow{3}{*}{$\mathrm{Xi}^{\wedge} 2$} & \multirow{3}{*}{$\mathrm{Yi}^{\wedge} 2$} \\
\hline & & $\begin{array}{c}\mathrm{ekr}= \\
1\end{array}$ & $\begin{array}{c}\text { ekr }= \\
1,3\end{array}$ & $\begin{array}{c}\mathrm{ekr}= \\
0,4\end{array}$ & & & & & \\
\hline & & $\mathrm{KR}$ & $\mathrm{KB}$ & SM & $x i^{*} y i$ & yi & $\mathrm{xi}$ & & \\
\hline 1 & $7.00-7.15$ & 107 & 0 & $\begin{array}{r}12 . \\
0\end{array}$ & 3808 & 21.90 & 173.89 & 30238.68 & 479.55 \\
\hline 2 & $7.15-7.30$ & 110 & 1.3 & $\begin{array}{r}12 . \\
0\end{array}$ & 3945.6 & 32.52 & 121.31 & 14716.32 & 1057.86 \\
\hline 3 & $7.30-7.45$ & 115 & 0 & $\begin{array}{r}12 . \\
0\end{array}$ & 4064 & 20.39 & 199.35 & 39741.05 & 415.59 \\
\hline 4 & $7.45-8.00$ & 118 & 2.6 & $\begin{array}{r}12 . \\
0\end{array}$ & 4243.2 & 35.31 & 120.17 & 14441.57 & 1246.73 \\
\hline 5 & $8.00-8.15$ & 114 & 0 & $\begin{array}{r}12 . \\
0\end{array}$ & 4032 & 20.05 & 201.11 & 40446.91 & 401.93 \\
\hline 6 & $8.15-8.30$ & 113 & 0 & $\begin{array}{r}12 . \\
0\end{array}$ & 4000 & 20.53 & 194.84 & 37963.95 & 421.45 \\
\hline 7 & $8.30-8.45$ & 114 & 0 & $\begin{array}{r}12 . \\
0\end{array}$ & 4032 & 20.57 & 195.97 & 38406.01 & 423.29 \\
\hline 8 & $8.45-9.00$ & 114 & 0 & $\begin{array}{r}12 . \\
0\end{array}$ & 4032 & 20.44 & 197.28 & 38920.88 & 417.69 \\
\hline 9 & $9.00-9.15$ & 114 & 0 & $\begin{array}{r}12 . \\
0\end{array}$ & 4032 & 19.94 & 202.21 & 40888.99 & 397.59 \\
\hline 10 & $9.15-9.30$ & 111 & 1.3 & $\begin{array}{r}12 . \\
0\end{array}$ & 3977.6 & 19.32 & 205.93 & 42405.25 & 373.10 \\
\hline & $\sum$ & & & & 126905.6 & 738 & 5737.60 & 1064300.51 & 17894.70 \\
\hline & Rata-rata & & & & & 23.05 & 179.30 & & \\
\hline
\end{tabular}

Sumber : data olahan (2018) 
Tabel 3. Hasil Matematis Antara Kecepatan-Kepadatan, Volume-Kepadatan dan Volume-Kecepatan

\begin{tabular}{|c|ll|}
\hline Mode & \multicolumn{1}{|c|}{ Model Greenshields } \\
\hline $\mathrm{S}-\mathrm{D}$ & $\mathrm{S}$ & $=50,14-4,83 * \mathrm{D}$ \\
\hline $\mathrm{V}-\mathrm{D}$ & $\mathrm{V}$ & $=10,37 * \mathrm{~S}-0,21 * \mathrm{~S}^{2}$ \\
\hline $\mathrm{V}-\mathrm{S}$ & $\mathrm{V}$ & $=50,14 * \mathrm{D}-4,83 * \mathrm{D}^{2}$ \\
\hline
\end{tabular}

Sumber : data olahan (2018)

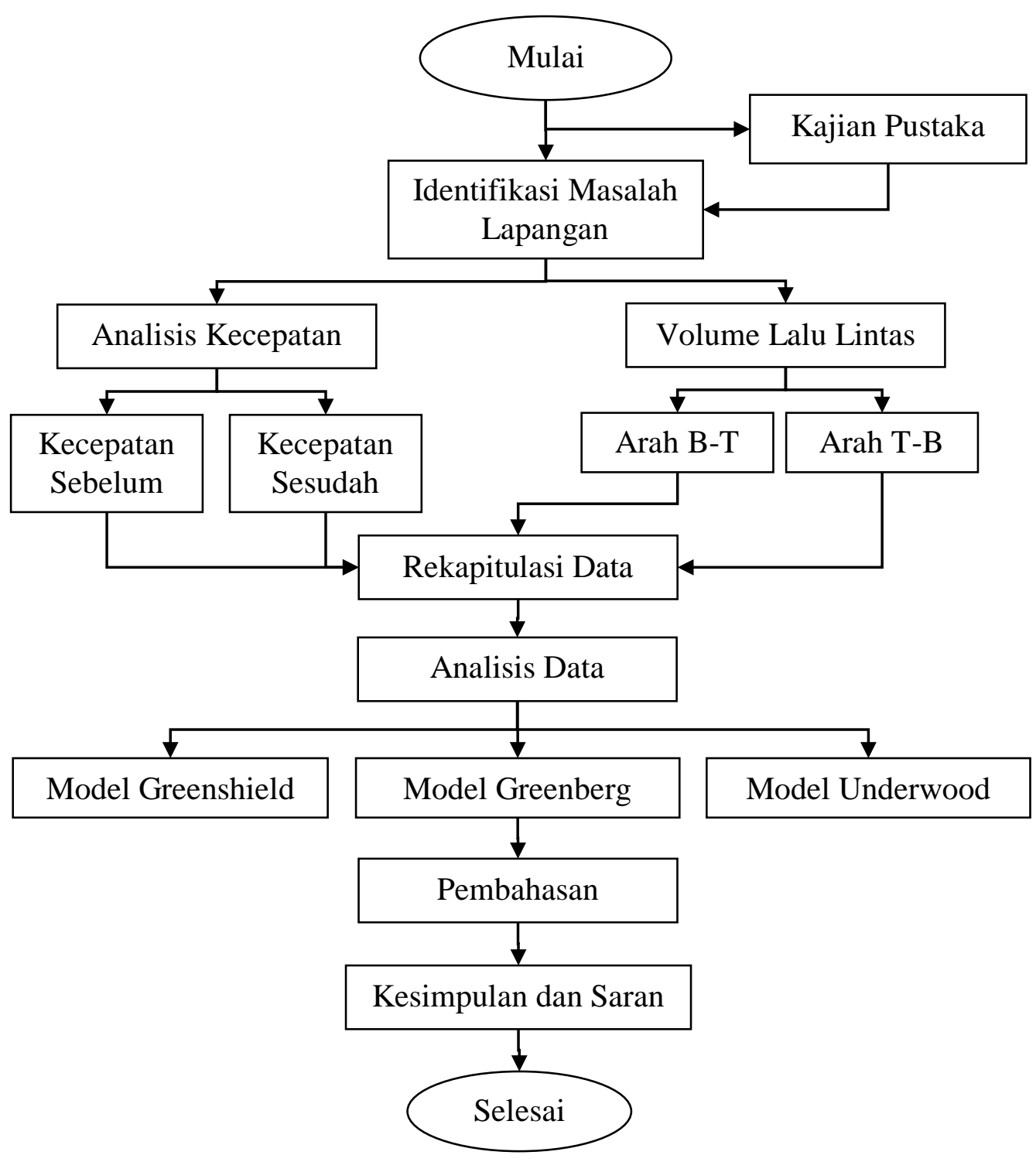

Gambar 1. Bagan Alir Penelitian 


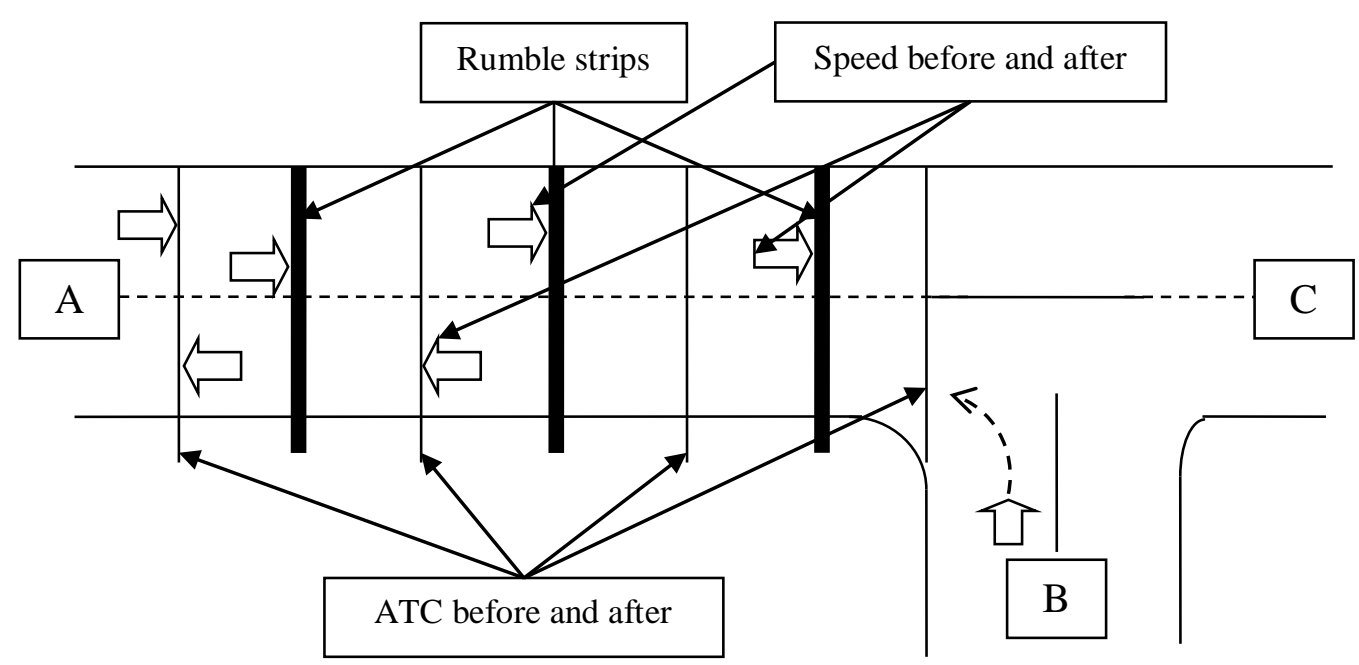

Gambar 2. Tata Letak Situasi Lapangan

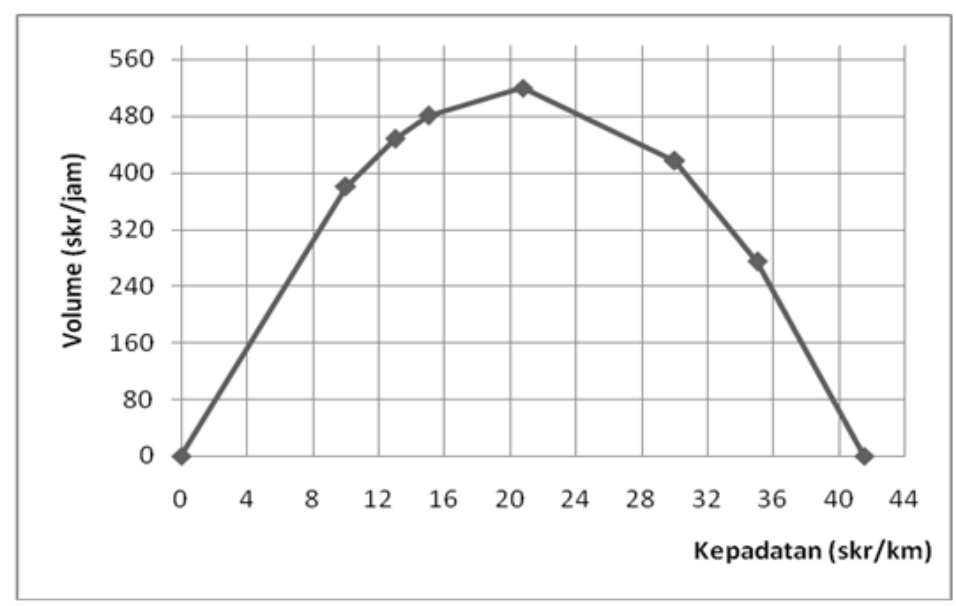

Gambar 3. Hubungan Kepadatan dan Volume 
Muhammad Idhan dan Hendra Saputra, Pemanfaatan Data Gelombang... 